\title{
pompalina
}

(8)

\section{Infeção urinária}

Autor(es): $\quad$ Gomes, Clara

Publicado por: Imprensa da Universidade de Coimbra

URL

persistente: URI:http://hdl.handle.net/10316.2/43122

DOI: $\quad$ DOI:https://doi.org/10.14195/978-989-26-1300-0_21

Accessed : $\quad$ 26-Apr-2023 11:14:46

A navegação consulta e descarregamento dos títulos inseridos nas Bibliotecas Digitais UC Digitalis, UC Pombalina e UC Impactum, pressupõem a aceitação plena e sem reservas dos Termos e Condições de Uso destas Bibliotecas Digitais, disponíveis em https://digitalis.uc.pt/pt-pt/termos.

Conforme exposto nos referidos Termos e Condições de Uso, o descarregamento de títulos de acesso restrito requer uma licença válida de autorização devendo o utilizador aceder ao(s) documento(s) a partir de um endereço de IP da instituição detentora da supramencionada licença.

Ao utilizador é apenas permitido o descarregamento para uso pessoal, pelo que o emprego do(s) título(s) descarregado(s) para outro fim, designadamente comercial, carece de autorização do respetivo autor ou editor da obra.

Na medida em que todas as obras da UC Digitalis se encontram protegidas pelo Código do Direito de Autor e Direitos Conexos e demais legislação aplicável, toda a cópia, parcial ou total, deste documento, nos casos em que é legalmente admitida, deverá conter ou fazer-se acompanhar por este aviso. 


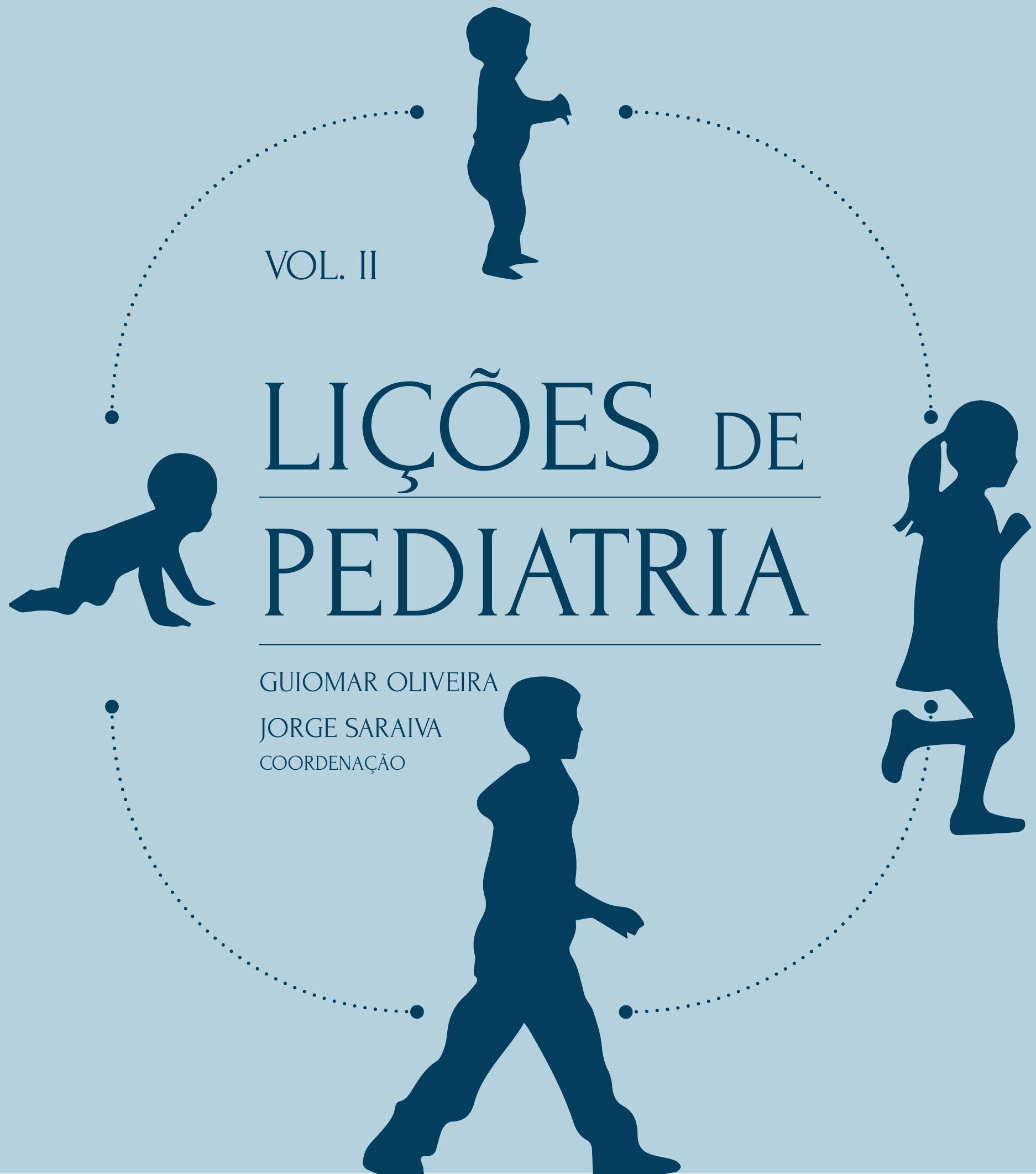


Capítulo 21.

Infeção urinária

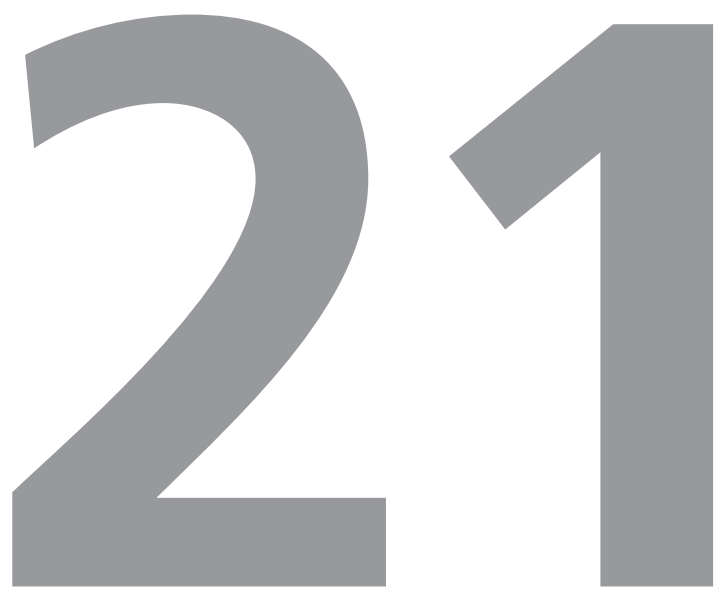

\section{Clara Gomes}




\subsection{CONTEXTO}

A infeção do trato urinário (ITU) é uma das infeções bacterianas mais frequentes na idade pediátrica. Define-se pela presença de bactérias na urina associada a sintomas.

Pelos oito anos cerca de 7\% das raparigas e 2\% dos rapazes já tiveram um episódio de ITU.

Pela sua frequência, por se poder associar a anomalia nefrourológica e pelo risco de lesão renal permanente que pode condicionar, a ITU tem sido alvo de múltiplos estudos para definir a melhor estratégia quanto ao diagnóstico, investigação e tratamento.

\subsection{DESCRIÇÃO DO TEMA}

\subsubsection{Etiopatogenia}

Em crianças saudáveis a urina do aparelho excretor urinário, incluindo a da bexiga, é estéril. A uretra é colonizada por bactérias. As malformações do aparelho urinário que favorecem estase urinária, a capacidade que algumas bactérias têm de aderir à mucosa uroepitelial (por exemplo algumas Escherichia coli com fímbrias) e a disfunção vesical são fatores predisponentes para o desenvolvimento de ITU.

Os agentes etiopatogénicos mais frequentes na ITU são da família das Enterobacteriaceae, nomeadamente a Escherichia coli (60 a 90\%), o Proteus mirabilis, a Klebsiella, o Enterobacter; e ainda os Enterococcus, as Pseudomonas, o Staphylococcus coagulase negativo e o Staphylococcus saprophyticus.

A maioria das ITU ocorre por via ascendente. Algumas crianças desenvolvem apenas cistite (infeção confinada à bexiga), outras pielonefrite aguda (PNA) ou ITU alta (infeção com envolvimento do parênquima renal) e numa minoria de casos, sobretudo em pequenos lactentes, pode ainda associar-se bacteriémia e sépsis. Tem sido proposto que a via hematogénea seria uma via de ITU nestes pequenos lactentes. Contudo, a microbiologia destas infeções e a elevada incidência de anomalias urológicas associadas, levantam a questão se a ITU tem origem hematogénea ou se não é apenas uma ITU ascendente que se associou a bacteriémia. Em cerca de um terço dos recém-nascidos com ITU documenta-se bacteriémia com o mesmo micróbio da urocultura, e uma parte desenvolve também meningite. O risco de bacteriémia vai diminuindo com a idade sendo muito baixo a partir dos três meses.

Quando as bactérias invadem o rim, desenvolve-se um processo inflamatório local que pode ativar processos imunes sistémicos com amplificação da resposta inflamatória, produção de citoquinas e quimioquinas. A exacerbação da lesão renal aguda favorece a evolução posterior para lesão cicatricial.

\subsubsection{Epidemiologia}

A incidência de ITU varia com a idade e o sexo e é difícil de estimar porque os estudos epidemiológicos publicados são heterogéneos quanto à sua definição e à metodologia utilizada para a colheita de urina. No primeiro ano e sobretudo nos primeiros seis meses de vida, é uma a uma vez e meia mais frequente no sexo masculino e a partir dos 12 meses passa a ser três vezes mais prevalente no sexo feminino. No recém-nascido 
de termo estima-se uma prevalência de 1.1\% mas, na criança até aos dois anos de idade com febre, sobe para $5 \%$.

Aos 16 anos estima-se uma incidência acumulada no sexo feminino de $11,3 \%$ versus $3,6 \%$ no masculino.

As crianças de raça caucasiana apresentam uma prevalência de ITU superior às de raça negra.

\subsubsection{ITU recorrente}

As raparigas têm maior predisposição para ITU recorrente do que os rapazes assim como as crianças que têm a primeira ITU em idade precoce. Estima-se que $3 / 4$ das crianças com uma ITU no primeiro ano de vida, e $40 \%$ das raparigas e $30 \%$ dos rapazes, com primeira ITU após o ano de vida, irão repetir outro episódio. As raparigas têm maior probabilidade de recorrência de ITU com a idade, o que não acontece nos rapazes.

Para efeitos de investigação imagiológica considera-se ITU recorrente pelo menos duas PNA, três cistites, ou uma PNA e uma cistite.

\subsubsection{Diagnóstico}

\section{Clínica}

Para o diagnóstico de ITU é necessário comprovar a presença de bactérias na urina e existirem queixas clinicas.

A PNA é mais frequente nas crianças mais pequenas e o principal sinal é a febre. Nos lactentes pode acompanhar-se de sintomas inespecíficos como irritabilidade, vómitos e má progressão ponderal e nos recém-nascidos pode nem existir febre e sinais e sintomas como letargia, recusa alimentar, gemido ou icterícia prolongada devem ser valorizados. Nas crianças mais velhas, o quadro clássico é a presença de febre e lombalgia mas a febre isolada é também uma forma de apresentação comum.

Pela clínica inespecífica o diagnóstico diferencial entre cistite e PNA nem sempre é fácil. Dum modo geral considera-se PNA ou ITU alta, a ITU com febre, a ITU em criança com menos de dois anos e a ITU associada a lombalgia. $\mathrm{Na}$ criança com dois ou mais anos, a ITU sem febre denomina-se cistite.

Nas crianças com menos de três anos, corretamente vacinadas, com febre (superior a 38 graus) sem foco, a PNA é a causa mais frequente de infeção bacteriana grave. Urina turva ou com odor fétido devem evocar o diagnóstico. Em crianças com mais de dois anos podem existir outros sinais e sintomas como disúria, polaquiúria, ou lombalgia.

$\mathrm{Na}$ história clínica podem identificar-se alguns dados que sugerem ITU associada a patologia grave subjacente: jacto urinário fraco, história sugestiva ou confirmada de ITU prévia, febre recorrente de etiologia desconhecida, diagnóstico pré-natal de malformação nefrourológica, história familiar de refluxo vesico-ureteral (RVU) ou doença renal, obstipação, sinais de disfunção miccional, massa abdominal, lesão medular ou má evolução ponderal.

A cistite manifesta-se habitualmente por disúria, polaquiúria, dor supra-púbica ou incontinência urinária, sem febre. No entanto, este quadro semiológico pode dever-se a outras patologias como vulvovaginite, parasitose intestinal ou alterações funcionais da micção.

Assim, a suspeita clínica de ITU na criança exige sempre a realização de análises de urina. 


\begin{tabular}{|l|l|l|}
\hline Teste & Sensibilidade \% (IC) & Especificidade \% (IC) \\
Esterase leucocitária & $83(67-94)$ & $78(64-92)$ \\
Nitritos & $53(15-82)$ & $98(90-100)$ \\
Esterase leucocitária e nitritos positivos & $93(90-100)$ & $72(58-91)$ \\
Leucócitos (microscopia) & $73(32-100)$ & $81(45-98)$ \\
Bactérias (microscopia) & $81(16-99)$ & $83(11-100)$ \\
Esterase leucocitária, nitritos e microscopia positiva & $99,8(99-100)$ & $70(60-92)$ \\
\hline
\end{tabular}

Adaptado de National Collaborating Centre for Women's and Children's Health, Commissioned by the National Institute for Health and Clinical Excellence. Urinary tract infection in children: diagnosis, treatment and long-term management. London: RCOG Press; 2007; Practice parameter: the diagnosis, treatment and evaluation of the initial urinary tract infection in febrile infants and young children. American Academy of Paediatrics. Paediatrics 1999; 103:843-52.IC- intervalo de confiança.

Quadro 1. Sensibilidade e especificidade da tira-teste e da urina tipo II no diagnóstico de ITU.

\section{Exames laboratoriais}

Para o diagnóstico é fundamental a colheita assética de urina por técnica correta e a realização de uma urocultura.

Como os resultados da urocultura não são imediatos, existem provas rápidas de rastreio de ITU como o exame de urina com tira-teste e a observação da urina ao microscópio que permitem estimar a probabilidade do diagnóstico e antecipar o início da terapêutica.

$\mathrm{Na}$ tira-teste considera-se urina alterada e sugestiva de ITU a positividade dos nitritos e da esterase leucocitária que indica a presença de leucócitos. Os nitritos resultam do desdobramento pelas bactérias dos nitratos urinários provenientes da dieta. A presença de nitritos é muito sugestiva de ITU mas a sua ausência não a exclui: algumas bactérias (gram-positivas) não os produzem ou se houver polaquiúria pode não haver tempo necessário para a sua formação.

Na urina tipo II valoriza-se para além da presença de nitritos e de leucocitúria ( $\geq 8$ leucócitos/ campo ou $\geq 40$ leuc/ $\mu$ l) a deteção microscópica de bactérias no sedimento urinário. Os resultados das diversas provas devem ser valorizados em conjunto (Quadro 1). Uma análise de urina tipo II com leucocitúria, nitritos positivos e bactérias é muito sugestiva de ITU. A urina deve ser examinada imediatamente após a colheita para evitar multiplicação de bactérias contaminantes.

A técnica correta de colheita da urina é fundamental para evitar erros de diagnóstico e suas consequências. Uma ITU que não se diagnostica atrasa o tratamento e pode favorecer a lesão renal e agravamento do estado geral do doente. Um diagnóstico incorreto de ITU por urina contaminada exige procedimentos terapêuticos e de investigação evitáveis e não isentos de riscos (iatrogenia).

Os métodos de colheita de urina para rastreio de ITU são o jato médio nas crianças com controle de esfíncteres e o saco coletor nas outras. Estas técnicas apresentam risco de contaminação da urina, principalmente o saco coletor. O risco deve ser reduzido com uma lavagem perineal 
correta (com água e sabão e não desinfetante) e substituição periódica do saco coletor (de 30 em 30 minutos).

A colheita por punção vesical (PV) aspirativa, suprapúbica, é a técnica ideal para evitar a contaminação da urina em crianças mais pequenas. No entanto, é um procedimento invasivo, doloroso e nem sempre consegue obter urina, o que pode ser melhorado se for guiado com ecografia.

A algaliação é um método também invasivo, tecnicamente mais fácil de executar e menos doloroso do que a PV, mas não é isento do risco de contaminação e no rapaz pode provocar traumatismo uretral. Tal como na colheita por jato médio, deverá ser desperdiçada a primeira porção de urina.

A urocultura da colheita por saco coletor só deve ser valorizada se fôr negativa - não permite diagnóstico de ITU devido à elevada taxa de contaminação. A PV, o cateterismo e o jato médio são as únicas técnicas consideradas asséticas e que devem ser usadas para confirmar o diagnóstico de ITU e como técnicas de colheita inicial nos doentes que necessitam de tratamento antibiótico urgente.

Tipicamente a ITU é provocada por um único microorganismo. Cada bactéria dá origem a uma colónia. Para o diagnóstico laboratorial de ITU é necessária uma elevada concentração de colónias na amostra urinária que vai depender do método da colheita da urina: por saco e jato médio considera-se positiva se $\geq 100.000\left(10^{5}\right)$ colónias por ml de urina, por PV e por cateterismo se $\geq 1.000\left(10^{3}\right)$ bactérias $/ \mathrm{ml}$.

Quando a urina é contaminada podem existir culturas mistas de bactérias e contagens inferiores sendo necessário confirmar com novas colheitas. A urocultura positiva é indispensável para o diagnóstico de ITU, mas isolada não permite o diagnóstico nem consegue avaliar a gravidade da infeção. Apenas os dados clínicos combinados com a urocultura permitem o diagnóstico seguro de ITU.

A bacteriúria assintomática é um exemplo da presença de bactérias na urina sem sintomas - não deve ser considerada uma ITU e não exige tratamento.

A sua prevalência é significativa: 2 a 3\% nos recém-nascidos do sexo masculino, 1.5 a 2\% nos lactentes e 0.8 a $2 \%$ em meninas com mais de dois anos com um pico de prevalência nas raparigas em idade escolar. Habitualmente confirma-se em uroculturas consecutivas crescimento significativo do mesmo gérmen, único e que não se acompanha de alterações do sedimento urinário, nomeadamente piúria, exceto nalgumas situações.

Habitualmente não condiciona complicações mesmo se associada a RVU, e por isso o tratamento é desnecessário e contraindicado pelo risco de selecionar estirpes mais agressivas.

Como nem sempre é fácil o diagnóstico diferencial entre cistite e PNA alguns exames laboratoriais podem ajudar: a proteína $\mathrm{C}$ reativa ou a procalcitonina elevadas e a presença de leucocitose neutrófila são a favor do diagnóstico de PNA.

A hemocultura pode também ser positiva, sobretudo em pequenos lactentes com maior risco de bacteriémia.

O cintigrama renal com ácido dimercaptosuccínico (DMSA) marcado com tecnécio 99-m efetuado na fase aguda, é o exame de eleição 
para confirmar o envolvimento do parênquima renal, mas não está disponível na prática clínica em muitos centros.

\subsubsection{Tratamento}

O objetivo do tratamento é aliviar a sintomatologia, erradicar a infeção mas sobretudo reduzir o risco de lesões parenquimatosas renais. A escolha do antibiótico, via de administração e duração do tratamento dependem da apresentação clínica mas também é fundamental conhecer os padrões locais de microbiologia e a sensibilidade aos antibióticos. Os principais agentes microbiológicos (Escherichia coli, Proteus e Klebsiella) vão alterando a sua sensibilidade de acordo com o uso habitual dos antibióticos. É necessário ir monitorizando, em cada centro, o padrão de sensibilidade que deve orientar o tratamento empírico inicial.

A terapêutica precoce e agressiva, isto é nas primeiras 48 a 72 horas de apresentação da ITU, pode prevenir a lesão renal. Deve ser iniciada imediatamente após colheita de urina correta, sobretudo nas crianças que apresentam febre elevada (superior a $39^{\circ} \mathrm{C}$ ) há mais de 48 horas, alteração do estado geral, lombalgia ou tenham imunodeficiência ou anomalias urológicas conhecidas.

Os critérios para internamento e/ou terapêutica endovenosa são:

- Todos os lactentes com menos de dois meses.

- Alteração do estado geral (aspeto tóxico, hipotensão arterial, desidratação, alterações hidroelectrolíticas).

- Via oral inviável (vómitos, diarreia).
- Doente imunocomprometido.

- Problema sócio-familiar que dificulte o cumprimento da terapêutica.

- Ponderar se suspeita de malformação urológica ou uropatia grave já conhecida.

- Falência de resposta ao tratamento oral.

Como a Escherichia coli é o gérmen predominante, o antibiótico inicial empírico deve ter em conta o seu padrão local de sensibilidade. Cerca de $50 \%$ das Escherichia coli são resistentes à amoxicilina ou ampicilina e numa percentagem variável à amoxicilina+ácido clavulânico, cotrimoxazol e cefalosporinas de primeira geração. Em crianças que estão sob profilaxia antibiótica ou que fizeram recentemente antibiótico por outro motivo, o risco de resistências a vários antibióticos é ainda maior e deve ser considerado. Nas crianças com ITU recorrente, a escolha empírica do antibiótico deve ter em conta a suscetibilidade dos agentes das ITU anteriores.

As cefalosporinas de $2^{a}$ e $3^{a}$ geração (cefuroxime, cefotaxime, cefixime e ceftriaxone) e os aminoglicosídeos (gentamicina e amicacina) são os agentes de primeira linha. Contudo estes antibióticos não são eficazes contra Enterococcus e na sua suspeita (anomalia urológica, manipulação do aparelho urinário, recém-nascido) deve associar-se ampicilina.

Em diversos estudos conclui-se que não se encontram diferenças significativas em nenhuma das variáveis analisadas (tempo médio de desaparecimento da febre, recorrência de ITU sintomática, lesão renal permanente) entre a administração antibiótica exclusivamente por via oral e a administração endovenosa (EV) de curta duração seguida de via oral ou entre a administração por via EV 


\begin{tabular}{|c|c|c|c|}
\hline Idade & Antibiótico & Duração & Observações \\
\hline Recém-nascido & $\begin{array}{l}\text { Ampicilina ev } 40-100 \mathrm{mg} / \\
\mathrm{kg} / \mathrm{dia}, 6 / 6 \text { horas } \\
\quad+ \\
\text { Gentamicina ev } \\
\text { 4mg/kg/dia, uma toma }\end{array}$ & 7-10 dias & $\begin{array}{l}\text { Se o quadro inicial não } \\
\text { tiver sido grave e evolução } \\
\text { favorável, considerar } \\
\text { completar tratamento com } \\
\text { antibiótico por via oral de } \\
\text { acordo com o gérmen } \\
\text { e antibiograma }\end{array}$ \\
\hline 1 mês $-<3$ meses & $\begin{array}{l}\text { Cefuroxime ev } \\
80-100 \mathrm{mg} / \mathrm{Kg} / \mathrm{dia}, 8 / 8 \text { horas }\end{array}$ & 7-10 dias & Pode passar a oral após apirexia* \\
\hline$\geq 3$ meses & $\begin{array}{l}\text { Cefuroxime-axetil oral* } \\
\text { 20-30 mg/Kg/dia, 12/12 } \\
\text { horas (máximo 1g/dia) }\end{array}$ & 7-10 dias & \\
\hline
\end{tabular}

Quadro 2. Tratamento empírico da PNA

de curta duração seguida da via oral versus a via EV exclusiva durante todo o tratamento. Assim, os doentes com ITU febril, sempre que o estado geral o permita e sem patologia nefro-urológica subjacente, podem ser tratados de modo seguro por via oral.

Quando se inicia pela administração parenteral esta deve manter-se até o doente melhorar clinicamente, ficar apirético e conseguir tolerar a medicação oral.

Nos recém-nascidos o risco de urosépsis é maior (12 a 30\%), pelo que neste grupo é mais seguro que o tratamento seja parentérico em regime de internamento durante sete a dez dias.

Vários estudos têm demonstrado eficácia em tratamentos de curta duração (dois a quatro dias) na erradicação das bactérias em crianças com ITU não febril. Não existem muitos dados em crianças com PNA mas a tendência é para reduzir o tempo de antibioterapia. As recomendações atuais vão no sentido de tratamento longo (sete a dez dias) para as crianças com PNA e tratamento curto (três a cinco dias) para as crianças imunocompetentes com ITU não febril.

Nos quadros 2 e 3 resume-se o protocolo usado no Hospital Pediátrico de Coimbra. O tratamento empírico da cistite pode ser efetuado com amoxicilina+ácido clavulânico por via oral.

Agentes orais como ácido nalidíxico e nitrofurantoína, que são excretados na urina mas não proporcionam níveis séricos adequados, não devem ser administrados para tratar ITU febril nas quais o envolvimento do parênquima renal é elevado assim como o risco de bacteriémia.

Vários estudos observacionais têm demonstrado que após o início do tratamento não são necessários controlos analíticos de urina se a evolução clínica for favorável nas primeiras 48 horas.

No entanto, se houver má evolução clínica sem resolução dos sintomas após 48 a 72 horas 


\begin{tabular}{|l|l|l|}
\hline Idade & Antibiótico & Duração \\
\hline$<2$ anos & Tratar como PNA & \\
\hline \multirow{4}{*}{ anos } & Amoxicilina + ácido clavulânico, oral & \\
& $40-50 \mathrm{mg} / \mathrm{Kg} /$ dia, 8/8 horas (12/12 horas para formulação DUO ou & \\
& ES) (máximo de ácido clavulânico - 1,2g/dia) & \\
\hline
\end{tabular}

*Se intolerância ao cefuroxime-axetil optar por amoxicilina + ácido clavulânico

Quadro 3. Tratamento da ITU não febril.

ou se o gérmen isolado não for sensível ao antibiótico instituído, a terapêutica empírica inicial deve ser revista e adaptada ao resultado do antibiograma. Outras causas para a falência terapêutica podem incluir uropatia obstrutiva e abcesso renal; nestas circunstâncias a ecografia renal e vesical pode ser útil.

\subsubsection{Profilaxia}

Nos últimos anos o uso de antibioterapia profilática, em dose baixa (habitualmente 1/3 da dose terapêutica) por rotina, após a primeira ITU tem sido contestado. Vários estudos, com algumas falhas metodológicas, não têm demonstrado claramente redução da recorrência de ITU e da cicatriz renal nas crianças sob profilaxia versus placebo, exceto em situações de RVU mais intenso onde parece ter algum efeito benéfico. $\mathrm{Na}$ verdade, evidência científica recente sugere que o RVU diagnosticado após ITU febril ou sintomática submetido a profilaxia com cotrimoxazol reduziu em $50 \%$ a recorrência de ITU, principalmente a febril e a associada a disfunção vesical, mas não teve efeito na redução de cicatriz renal.

A prática mais consensual consiste na administração de profilaxia em determinadas situações como crianças com RVU intenso ( $\geq$ a grau III), ITU recorrente e nas crianças com anomalias urológicas e risco de PNA até à cirurgia.

Os fármacos mais adequados são o trimetoprim, cotrimoxazol, cefadroxil, cefatrizina ou nitrofurantoína, administrados no terço da dose terapêutica, numa toma oral à noite.

\subsubsection{Outras terapêuticas}

A disfunção vesical, alteração frequente em raparigas entre os quatro e os 12 anos, é uma causa de ITU. Depois de excluídas causas neurológicas e urológicas, deve-se investir na terapêutica não farmacológica com o reforço de ingestão hídrica adequada, micções regulares e completas e controle da obstipação. Pode ser necessária terapêutica farmacológica com oxibutinina ou outros fármacos de acordo com o tipo da disfunção.

Os processos inflamatórios do parênquima renal na fase aguda da PNA estão relacionados com a génese da cicatriz renal que tem sido o enfoque da investigação e tratamento. Alguns estudos têm avaliado o papel potencial de agentes anti-inflamatórios como corticóides (dexametasona e metilprednisolona) associados aos antibióticos na fase aguda. Os resultados parecem apontar para redução do risco de cicatriz renal sem afetar 
a taxa de recorrência da ITU. Esta pode vir a ser uma vertente terapêutica com interesse clínico.

\subsubsection{Investigação imagiológica}

O objetivo principal na investigação imagiológica após uma ITU consiste em detetar anomalias congénitas ou adquiridas do rim e do trato urinário ou RVU que são fatores de risco para ITU recorrente e lesão renal.

Nos últimos anos a investigação de ITU tem sido um dos temas mais controversos com tendência a ser simplificada.

A ecografia renal, um exame inócuo, de fácil acesso é um exame de primeira linha na avaliação após uma ITU. É pouco sensível para o diagnóstico de PNA e de RVU. Contudo, permite identificar dilatação das vias urinárias ou alterações como localização, assimetria renal ou alterações vesicais e ajuda a orientar os exames posteriores.

As indicações mais consensuais para a realização de ecografia são: em crianças com menos de dois anos com primeiro episódio de PNA; em qualquer criança com ITU febril recorrente; crianças com uma ITU e história familiar de doença renal ou urológica, má progressão ponderal ou hipertensão arterial e falência de resposta a terapêutica antibiótica apropriada.

A ecografia com doppler aumenta a sensibilidade para o diagnóstico de PNA, mas é menos disponível e mantem escassa sensibilidade para detetar RVU.

A cintigrafia renal com DMSA é o método de eleição para identificar lesão renal aguda (PNA) e lesão crónica (cicatriz) com sensibilidade muito superior à da ecografia e eco doppler. Estudos experimentais demonstram que atinge uma sensibilidade de 85 e especificidade de 95\% face ao resultado histopatológico.

De um modo geral considera-se anormal se existe uma redução da função dum rim relativamente ao outro superior a $5 \%$ ou evidência de zonas de hipocaptação cortical com distorção ou perda do contorno renal normal. Estas alterações podem ser agudas e resolverem, ou permanecerem. O cintigrama renal tardio, que deve ser efetuado pelo menos seis meses após o episódio de ITU, permite fazer o diagnóstico diferencial: a existência de defeitos de captação nesta fase representa cicatrizes que permanecerão como sequelas.

Em crianças com menos de dois anos com PNA e maior risco de desenvolver cicatriz renal, o cintigrama renal na fase aguda (primeiros cinco a sete dias após o início da febre) pode ser útil para orientar a estratégia diagnóstica posterior - necessidade de cistografia ou cintigrama renal tardio. Um DMSA normal durante o primeiro episódio de ITU febril exclui a presença de RVU intenso sem risco de cicatriz posterior. Pelo contrário um DMSA alterado na fase aguda é preditivo de RVU significativo com maior risco de recorrência da ITU e de cicatriz renal.

Na prática, a indisponibilidade do DMSA nos primeiros dias de ITU febril em muitos centros, limita o seu uso.

A cistografia direta é o exame ideal para diagnosticar RVU. Pode ser radiológica, isotópica ou ecográfica. O procedimento consiste na introdução de produto de contraste (radiológico, 
isotópico ou ecogénico) dentro da bexiga e avaliar se existe fluxo ascendente durante o preenchimento e esvaziamento vesical. É sempre necessária a algaliação o que pode favorecer o aparecimento de ITU. Existe outra possibilidade de cistografia, a indireta quando se realiza um cintigrama renal de eliminação e a criança, já com controle de esfincteres, é capaz de colaborar retendo a urina a nível vesical com o marcador isotópico. É muito menos sensível que a cistografia direta mas dispensa a algaliação.

A cistografia radiológica ou cistouretrografia miccional é o método de eleição para o estudo anatómico da bexiga e da uretra permitindo avaliar de forma mais completa o RVU quando existe. A classificação internacional de RVU baseia-se neste tipo de cistografia: RVU de grau I se atinge apenas o ureter; grau II se atinge a pélvis renal mas sem dilatação; grau III se atinge a pélvis renal e associa dilatação ligeira a moderada do ureter, pélvis e cálices; grau IV se a dilatação do excretor é moderada com tortuosidade do ureter; grau $\mathbf{V}$ se a dilatação do excretor é severa com grave tortuosidade do ureter e perda da impressão das papilas renais. É o único método que permite também avaliar a uretra e o que se deve efetuar na suspeita de válvulas da uretra posterior (dilatação pielo-calicial bilateral ou alterações da ecografia vesical em rapazes).

A cistografia isotópica tem menos dose de radiação mas não permite um estudo anatómico da bexiga e vias urinárias. Pode ser o primeiro exame para investigar RVU nas raparigas ou nos rapazes cuja ecografia não mostre alterações vesicais suspeitas de válvulas da uretra posterior, no seguimento e controle de RVU e na investigação familiar de crianças com RVU.
A cistografia ecográfica, a menos usada, é isenta de radiações mas requer treino do operador para obter um rendimento semelhante ao das outras técnicas.

\subsubsection{ITU, RVU e cicatriz renal}

Após uma PNA deteta-se RVU em 30 a 40\% em crianças com menos de dois anos e em 20 a $25 \%$ de raparigas em idade escolar com ITU recorrente.

O RVU é uma anomalia urológica comum na criança que se define pelo fluxo retrógrado de urina da bexiga até ao ureter ou ao bacinete. A sua prevalência exata é desconhecida mas estudos apontam para uma taxa de 1 a $6 \%$ em idade pediátrica. A maioria dos casos de RVU primário é diagnosticada na investigação de uma ITU.

O papel do RVU no desenvolvimento de PNA foi documentado em trabalhos experimentais nos anos 60 e 70. Crianças mais pequenas, nos primeiros dois anos de vida ficavam mais suscetíveis a sofrerem sequelas renais pelas pielonefrites e a recorrência de ITU era superior nas crianças com RVU.

Em estudos com realização de cintigrama renal na fase aguda tem-se documentado lesão renal aguda em 40 a $70 \%$ dos doentes com menos de dois anos e ITU febril. São fatores favorecedores de lesão renal aguda o atraso de início da terapêutica antibiótica eficaz (> 48 a 72H) e a existência de RVU mais intenso (de grau III ou superior).

Seis a $15 \%$ dos doentes com menos de dois anos vão desenvolver cicatriz renal após a primeira PNA, sendo raro o seu aparecimento após os quatro anos. A baixa idade (menos de dois anos), 
o atraso no tratamento eficaz, a ITU recorrente, o RVU intenso e a uropatia obstrutiva são os fatores de risco para lesão definitiva - a cicatriz renal. É esta lesão sequelar que pode condicionar hipertensão arterial, proteinúria persistente e evolução para insuficiência renal terminal e que passou a ser o foco que assume maior relevância na orientação da ITU.

Nos últimos anos tem-se questionado o interesse da cistografia de rotina em todas as crianças com ITU. O diagnóstico do RVU e a possibilidade de correção cirúrgica parecia ser a solução para prevenir lesão renal. No entanto, depois do entusiasmo inicial nos anos 80, começou a verificar-se que muitos casos de RVU resolviam espontaneamente, e que algumas crianças em que se resolvia cirurgicamente o RVU, continuavam a ter ITU repetida e noutras, mesmo sem ITU aparente, as lesões renais evoluíam. Alguns defeitos renais atribuídos a cicatriz eram na verdade lesões displásicas pré-natais. O papel do RVU não é então suficiente nem necessário para o desenvolvimento da lesão cicatricial, e a eficácia do tratamento do RVU na prevenção de cicatriz também é controverso em vários estudos.

Assim, apesar do risco de cicatriz renal poder aumentar com RVU mais intenso, não é claro nos estudos, que o benefício, em diagnosticar e tratar o RVU por rotina em todas as crianças, ultrapasse os riscos e custos inerentes.

As guidelines do National Institute for Health and Clinical Excellence (NICE) publicadas em 2007 constituíram uma mudança radical na orientação da ITU com redução significativa na investigação imagiológica. Estas orientações sugeriam a cistografia nas crianças com idade inferior a seis meses e ITU recorrente (definição atrás) ou atípica.
Definiam ITU atípica como toda a ITU manifestada com doença grave, jato urinário fraco, massa abdominal ou vesical, creatinina sérica elevada, septicémia e infeção por microorganismos que não a Escherichia coli ou ITU que não responde ao tratamento em 48 horas. Sugeriam ainda a possível necessidade de realização de cistografia nas crianças entre os seis meses e os três anos com ITU atípica ou recorrente e dilatação pielocalicial na ecografia renal, jato urinário fraco, ITU não causada pela Escherichia coli e história familiar de RVU.

Em 2011 foram publicadas as orientações da Academia Americana de Pediatria que deixaram de recomendar a cistografia de rotina para todas as crianças com a primeira ITU febril e a propõem apenas após a segunda ITU, exceto se existirem circunstâncias clínicas atípicas ou complexas ou se a ecografia renal revelar hidronefrose, cicatrizes renais ou achados sugestivos de RVU de grau elevado (IV ou V) ou de uropatia obstrutiva.

A tendência atual é realizar cistografia nas crianças com dois ou mais episódios de PNA e nas crianças com uma PNA e história familiar de doença renal ou urológica, ou má progressão ponderal, ou hipertensão arterial, ou se a ecografia renal ou o cintigrama renal revelarem alterações.

Tradicionalmente a cistografia era diferida pelo menos três a quatro semanas após a ITU para evitar falsos positivos de RVU. Atualmente preconiza-se que a altura em que é feita não influencia a presença ou a gravidade do RVU, podendo ser efetuada durante o tratamento da ITU, logo que a criança esteja assintomática. 


\subsubsection{Vigilância a longo prazo}

As crianças com ITU recorrente ou associada a anomalias nos exames imagiológicos devem ser vigiados regularmente e a longo prazo. As cicatrizes renais, sobretudo quando são bilaterais, podem condicionar proteinúria, hipertensão arterial ou alteração da função renal que é necessário monitorizar e tratar.

\subsection{FACTOS A RETER}

Para o diagnóstico de ITU é indispensável a realização de uma urocultura com colheita assética de urina.

O tratamento empírico inicial de uma ITU depende do estado clínico da criança e deve ter em conta as sensibilidades locais das bactérias mais frequentes; este conhecimento pressupõe uma monitorização regular do padrão de sensibilidade em cada centro.

A tendência atual é para não efetuar investigação imagiológica por rotina a todas as crianças após uma ITU, mas valorizar aspetos que podem indicar maior risco de lesão renal.

Os pais devem ser alertados para reconhecerem sintomas sugestivos de ITU e a importância do diagnóstico e tratamento precoces.

Os protocolos são linhas de orientação, que devem estar em contínua atualização. 